\title{
Conservative technique for restoration of anterior teeth: clinical case report
}

\begin{abstract}
This work aims to present a technique for resolving cases with aesthetic requirements using guides that facilitates the implementation of restorative procedures without the need for high manual sculpture skill to dental professional and reduced time. Fractures and wear tooth, poor dental position, trauma and dissatisfaction aesthetics are the major causes of seeking patients by the dentist. All these problems could be rehabilitated with indirect or direct restorations. The choice of the ideal material should consider some factors, such as the rehabilitation area, space available, the aesthetical potential of each material, the translucency of the adjacent teeth, type of reminiscent and antagonist that occlude with the new restoration. Direct restorations have good predictability, resistance load, longevity and compared with indirect restorations have greater preservation of dental tissues, low cost and fewer clinical sessions. However, restorative aesthetic works mainly require skill and practice of the dentist. The clinical case shows an alternative technique for performing aesthetic rehabilitation treatment with direct restorations with resin composite. The described technique was an excellent choice to ensure proper sculpture and anatomy of the anterior teeth. Respecting the principles of adhesion and operative procedures for performing direct restorations was possible to obtain an aesthetic and functional result favorable in less time.
\end{abstract}

Keywords: composite resin restoration, dental esthetics, rehabilitation
Volume 7 Issue 4 - 2017

\author{
Leandro Maruki Pereira,' Caio C sar Dias \\ Resende,' Renata Borges Rodrigues, ${ }^{2}$ \\ Alexandre Yukio Maruki, ${ }^{3}$ Paulo Cezar \\ Simamoto Junior, ' Veridiana Resende Novais ${ }^{2}$ \\ 'Department of Occlusion, Fixed Prosthodontics and Dental \\ Materials, Federal University of Uberlandia, Brazil \\ ${ }^{2}$ Department of Operative Dentistry and Dental Materials, \\ Uberlandia Dental School, Federal University of Uberlandia, \\ Brazil \\ ${ }^{3}$ Dental technical, Uberlandia, Brazil
}

Correspondence: Veridiana Resende Novais, Department of Operative Dentistry and Dental Materials, Uberlandia Dental School, Federal University of Uberlandia, Av Par, Tel 55-3432182255, Fax 55-34-32182279,

Email veridianaresende@hotmail.com

Received: April 18,2017| Published: June 07, 2017

\section{Introduction}

The human beauty is one of the greatest mysteries of humanity, the first impression concentrated is in the beauty of face and body proportions. Beauty studies ${ }^{1-3}$ are conducted since ancient times, considering how attractive something that achieves harmony between the lines or involving what was known as the golden ratio. ${ }^{3}$ The smile is something essential in the beauty of face, and the important criteria are white and aligned teeth, and harmony of the lips. 4 However, factors such as bruxism, dental injuries, erosions and abrasions can cause wear dental in anterior teeth leading to disharmony smile ${ }^{5,6}$ The evolution in adhesive dentistry has increased the indication of esthetic restorative procedures and various techniques and materials are described as alternatives of anterior teeth rehabilitation. The indirect technique using ceramics materials is an excellent choice for reanatomization of anterior teeth, present good longevity and maintenance of color. So, require greater number of session's clinics, higher dental wear sessions and cost compared to direct techniques. Direct techniques using composite resins are an excellent alternative to smile rehabilitation devolving dental aesthetics ${ }^{7}$ featuring accepted longevity and low cost. ${ }^{7}$ Success rate of $85 \%$ after 7 years in function were founded to restorations using composite resins in anterior teeth, needing only repairs or polishing. ${ }^{8,9}$ Direct techniques using composite resins require the surgeon ability. ${ }^{5}$ Some techniques are described using the diagnostic wax-up and silicone palatine guides to lead them to simulate the aesthetic of work and occlusal function pre-establishment during planning. ${ }^{5-12}$ The diagnosis waxing and mock-up prior to implementation of the final work allows the patient to have predictability and acceptance related to the final aesthetics. ${ }^{3}$ Silicone palatine guides allow to be entered on the first increment resin according to what was planned, however require profissional's ability and experience perform the anatomy of the buccal surface. Several techniques are described and used for making restorations and reanatomization of anterior teeth using composite resin, though still require experience and professional ability to the success of the rehabilitation. This case report presents an easy technique for making restoration of anterior teeth using silicone tabs that allow reanatomization and copy of the anatomical details of both buccal and palatine surface obtained in wax.

\section{Case presentation}

A 45-year-old, male, presented great dissatisfaction with their smile (Figure 1A). The patient had vertical dimension of occlusion decreased and absence of posterior occlusion stability resulting in fractured restoration (Figure1B) and worn teeth and presented unsatisfactory Class IV composite resin restoration in the upper left central incisor. After reestablish vertical dimension of occlusion (VDO) posterior with temporary crown placed in dental implants, there was the need to reestablish the anterior contacts and guides to get mutually protected occlusion. After clinical and radiographic examination, was proposed as a treatment plan the making of direct composite resin restorations due to the need of a few clinical sessions, low cost, repair facility and for being conservative treatment option. The patient was informed and consented to perform the proposed treatment plan. Irreversible hydrocolloid impression (Hydrogum, Zhermack, Badia Polesine, RO, Italy) was performed and the models were articulated on a semi-adjustable articulator by means of the face bow in the maximum intercuspidation position as had already been reestablished the VDO. In the same clinical session were performed photographs, and by Digital smile design ${ }^{14}$ planning was carried out (Figure 2) for better communication with the dental technician to guide 
you through the wax on the format of planning and position of the teeth (Figure 3A). From the wax was obtained two silicone matrices to guide the accomplishment of direct restorations. To reproduce the palatal portion of the teeth was made a palatal silicone guide using silicone condensation (Zetaplus ${ }^{\circledR}$, Zhermack, Badia Polesine, RO, Italy) (Figure 3B). For the anatomization of buccal surface was made a buccal silicone guide using silicone transparent addition (Elite transparente ${ }^{\circledR}$, Zhermack, Badia Polesine, RO, Italy) that allows the transfer the aesthetic characteristics of the wax to the mouth (Figure 3C). The buccal silicone guide was made according to manufacturer's instructions, injected on the all buccal surface of the wax on stone model of the anterior teeth and then taken to a eliminator bubbles pan (VH Produtos Odontologicos, Sao Paulo, SP Brazil), to eliminate bubbles in the transparent silicone guide. Unsatisfactory restorations were removed and was making bevel with a diamond bur (\#2134, KG Sorensen, Cotia, SP, Brazil). Prior to the restorative procedure was performed prophylaxis with rubber cups (Roda, Microdont Ltda., Sao Paulo, SP, Brazil) and pumice (Asfer Industria Quimica Ltda., Sao Caetano do Sul, SP, Brazil) in the anterior patient's teeth and then made relative isolation area. It was used a three-step adhesive system. The acid attack was made on the teeth using phosphoric acid $37 \%$ (Condac 37, FGM Produtos Odontologicos, Joinville, SC, Brazil) applying 30 seconds in enamel and 15 seconds in dentin, (Figure 4A) and then applying chlorhexidine for a minute to prevent degradation hybrid layer (Figure 4B). ${ }^{13}$ The substrate was dried using absorbent paper (Figure 4C) and then applied the primer of adhesive system Adper Scotchbond Multi-PurposeTM (3M ESPE, St. Paul, MN, EUA) (Figure 4D). It waiting time volatilization of the solvent, and then the teeth were separated using a polyester strip for adhesive application of the same system (Figure 4E). The polymerization was performed for 20 seconds with LED light (Radii-Cal - SDI, Bayswater, Australia) with $1.200 \mathrm{~mW} / \mathrm{cm} 2$. Polyester strips were removed and the upper left central incisor was isolated of adjacent teeth using a thin teflon strip (Viqua, Brasil, Assunção, Chile). Using a spatula for resin was inserting a layer thin translucent enamel composite resin (A2 Enamel, Empress Direct, Ivoclar Vivadent) on upper left central incisor on the palatal silicone guide and it was adapted to the tooth to be restored (Figure 5A). The composite resin was light cured as recommended by the manufacturer with LED light (Radii-Cal - SDI, Bayswater, Australia). The same procedure was performed for upper right central incisor (Figure 5B). A resin composite simulating dentine color (A3 Dentin Empress Direct, Ivoclar Vivadent, Schaan, Liechtenstein) was used for sculpting the developmental grooves and dentinal lobes (Figure 6). The buccal silicone guide was proved in order to analyze the correct adaptation or any interference of the previous resin layers that have been applied (Figure 7A). For the making the final resin composite layer corresponding to the artificial enamel was used to A3 color resin enamel (A3 Enamel, Empress Direct, Ivoclar Vivadent, Schaan, Liechtenstein) that was inserted in the region of upper right central incisor on the buccal silicone guide (Figure 7B) and then adapted to the teeth and pressed (Figure 7C). On the buccal silicone guide a source of LED light (Radii-Cal - SDI, Bayswater, Australia) was applied (Figure 7D). The matrix was removed and another time a source of LED light was applied. After polymerization of the resin, shape and texture are finalized, however, excess resins are visible due to material flow (Figure 8). Was used scalpel blade No.15 for the removal of excess (Figure 9) and the use of conical diamond burs to remove excess cervical (Figure 10). The same procedure was done for upper left central incisor, upper right lateral incisor and upper left lateral incisor, upper canines. It was performed the polishing with paste (Diamond R, FGM, Produtos Odontologicos, Joinville, SC, Brazil) and rubber boots (KG Sorensen, Cotia, SP, Brazil). Due to the use of buccal silicone guidewhich transferred all the contours and the macrotexture waxing for the composite resin restoration, it was not necessary to use burs to anatomization restorations (Figure 11). The patient was placed in a vertical position for the analysis of occlusion, the settings in centric relation and movements of protrusion and laterality using with conical diamond fine-grained and extrafine (KG Sorensen, Cotia, SP, Brazil), finish were checked. The polishing was carried out again in areas that adjustments were made (Figure 12). A-B shows the final appearance patient smile, showing that rehabilitation using direct composite resin restoration returned aesthetics, naturalness and harmony to the smile of the patient, respecting the principles of occlusion and even restoring oral function. (Figure 1A, 12A) shows the appearance of the initial and final smile after rehabilitation protocol that significantly changed the aesthetic and functional harmony. The Figure 13 shows two-year follow-up.
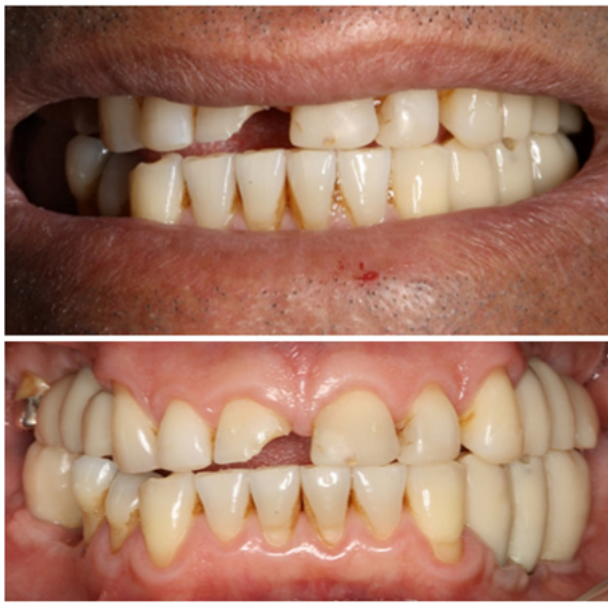

Figure I (A\&B) Preoperative photographs showing presenting fractured and eroded teeth, disharmonious relative with the lip.

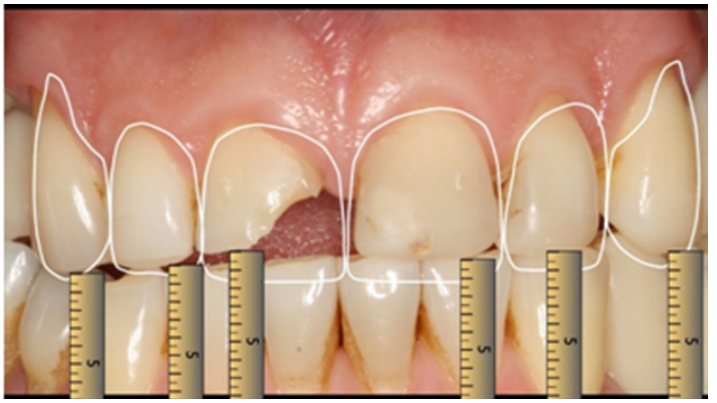

Figure 2 Digital smile design performed for making the Smile project.

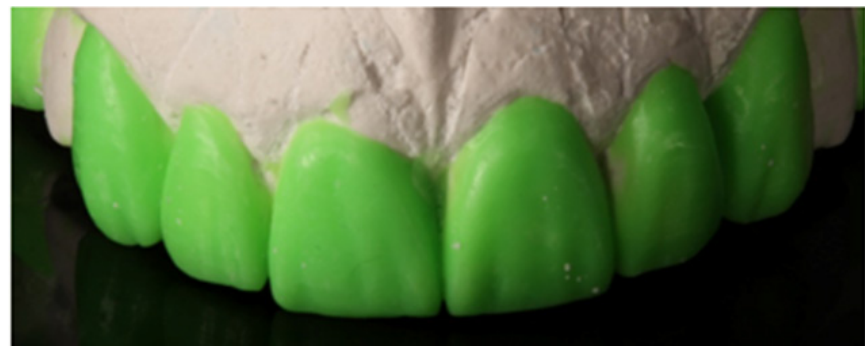

Figure 3 (A) Wax-up diagnosis through the wax-up were performed silicon guide. 


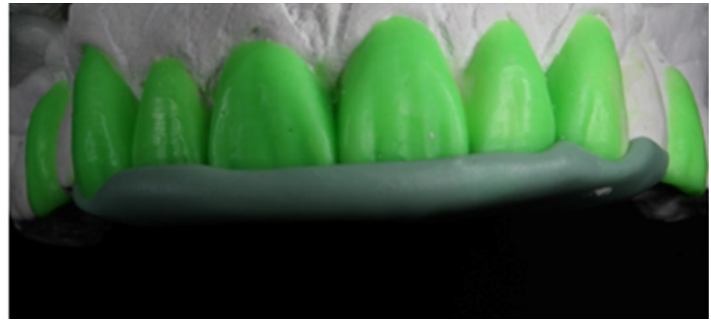

Figure 3 (B) Palatal silicone guide made from condensation silicon.

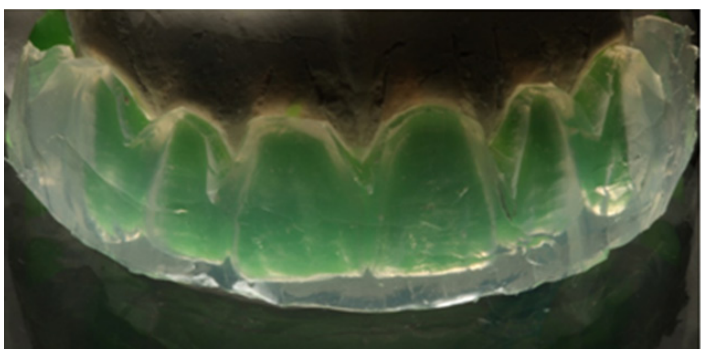

Figure 3 (C) Buccal silicone Guide made from transparent silicone condensation to anatomization of buccal surface.

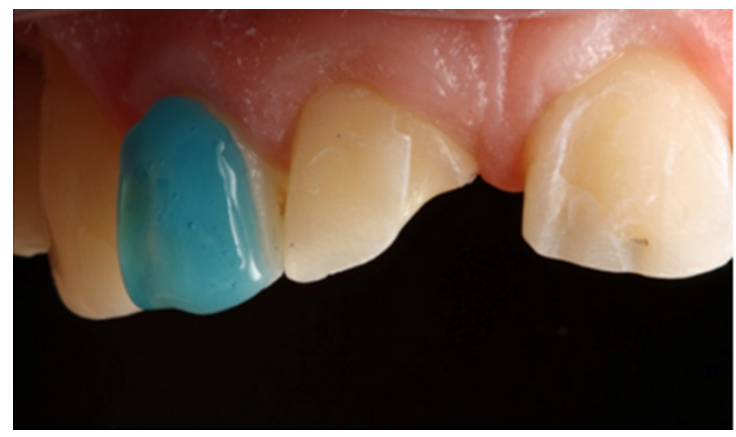

Figure 4 (A) Conditioning of the dental substrate using $37 \%$ phosphoric acid for 15 seconds on dentin and 30 seconds on enamel.

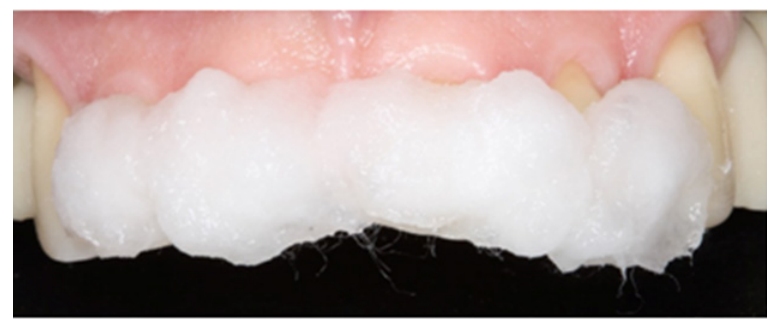

Figure 4 (B) After washing application of chlorhexidine for I minute.

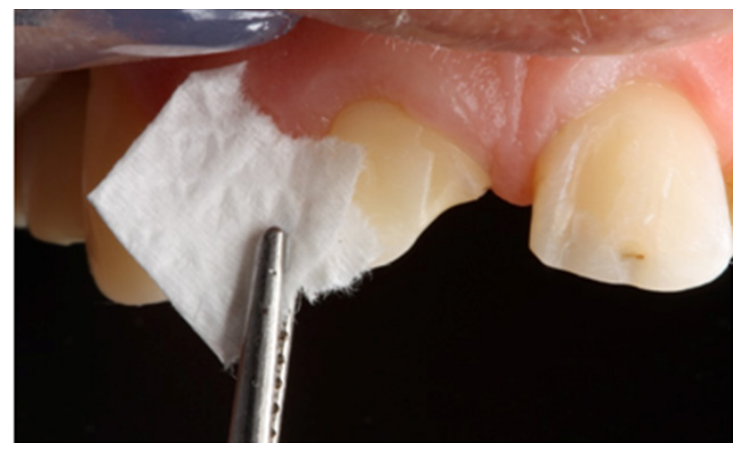

Figure 4 (C) Drying with tissue paper.

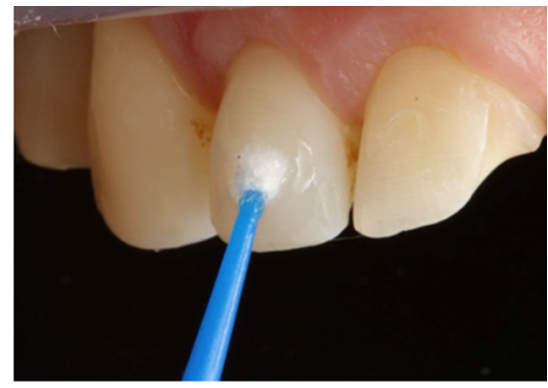

Figure 4 (D) Application of primer.

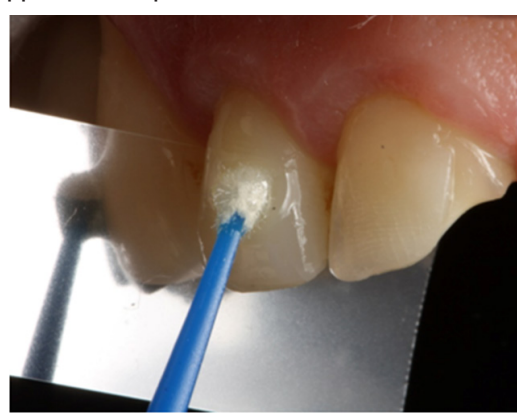

Figure 4 (E) Application of bond.

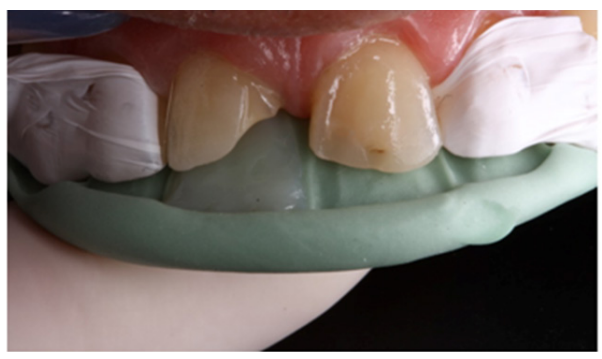

Figure 5 (A) Adjacent teeth isolated using Teflon.

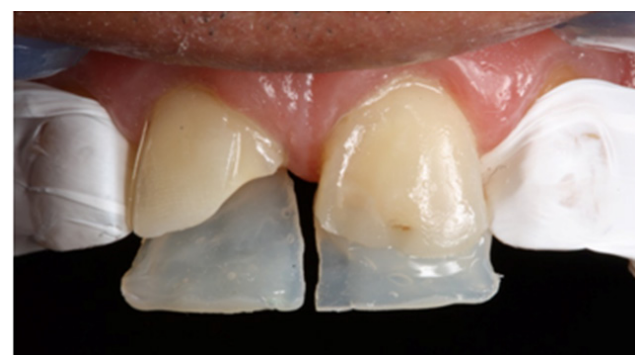

Figure 5 (B) Resin composite increment in the palatal region of the palatal silicone guide.

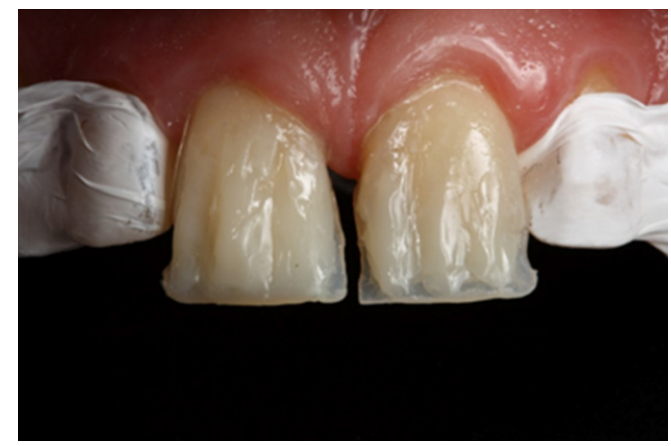

Figure 6 Resin composite simulating dentine color. 


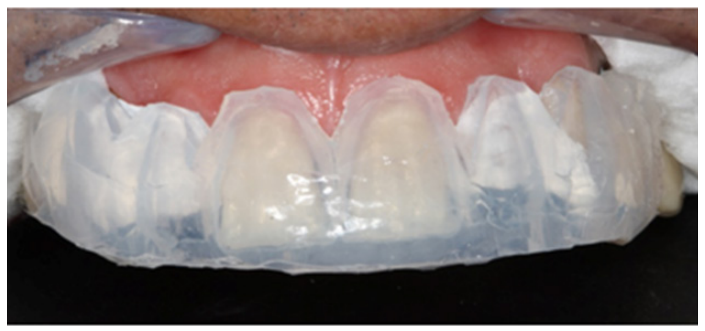

Figure 7 (A) Analysis of the insertion of the buccal silicone guide.

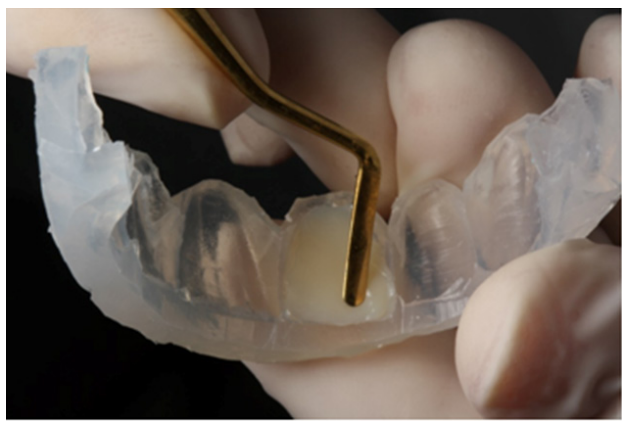

Figure 7 (B) Enamel resin layer applied over the vestibular guide.

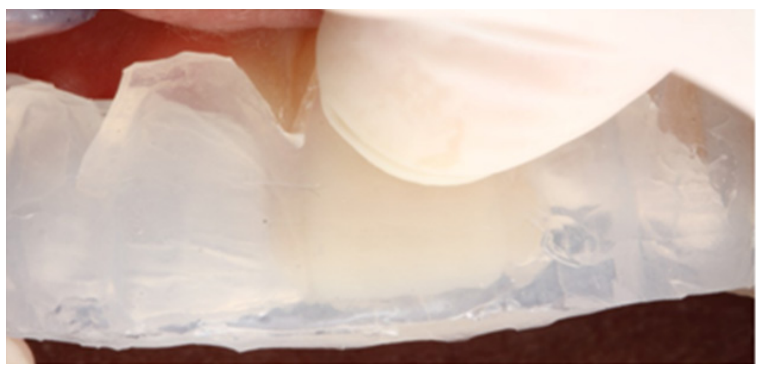

Figure 7 (C) Vestibular guide adapted and pressed in teeth.

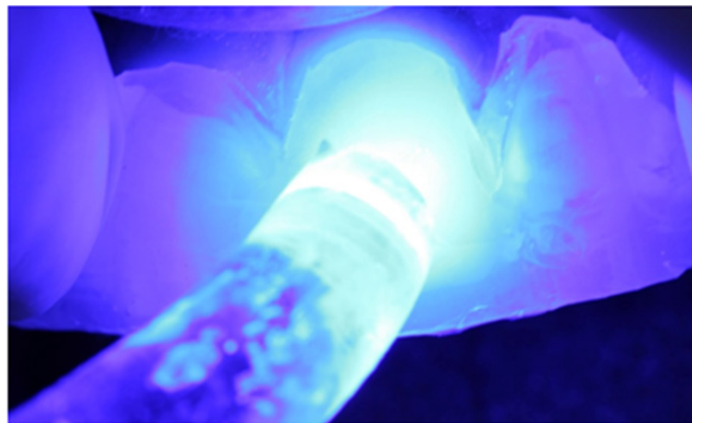

Figure 7 (D) Light curing the composite through the silicon guide.

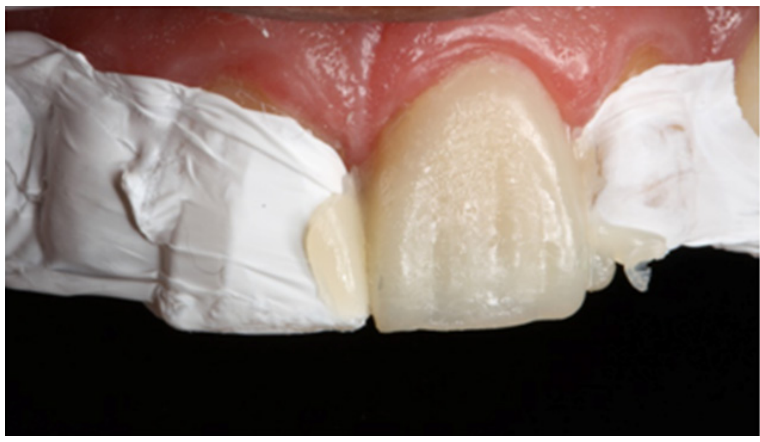

Figure 8 Appearance of the resin composite after removing the silicon guide.

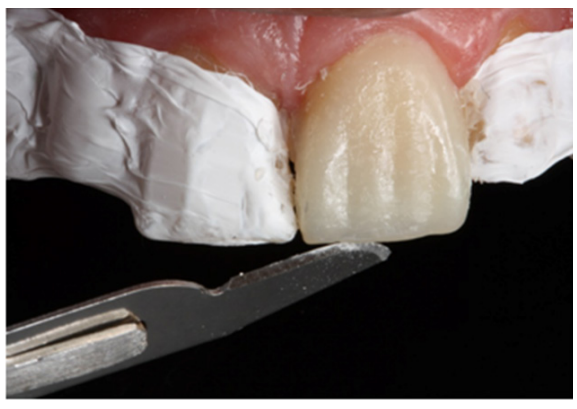

Figure 9 Removal of excess using a scalpel blade.

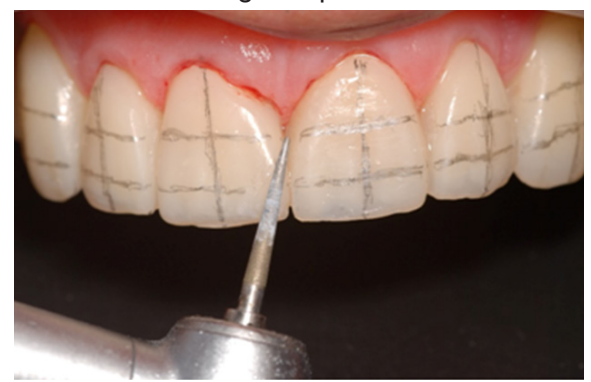

Figure 10 Aesthetic adjustments and cervical excess after the end of the facets in upper dental elements.

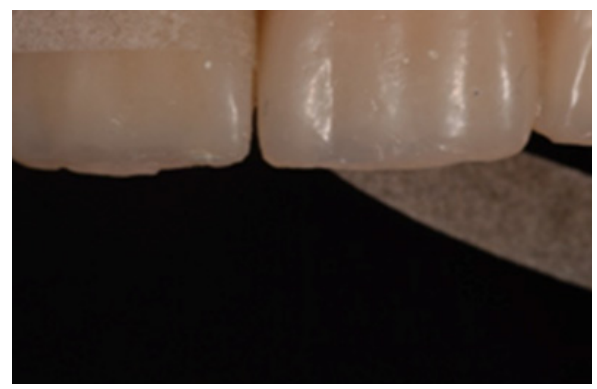

Figure II Finish using sandpaper strips.

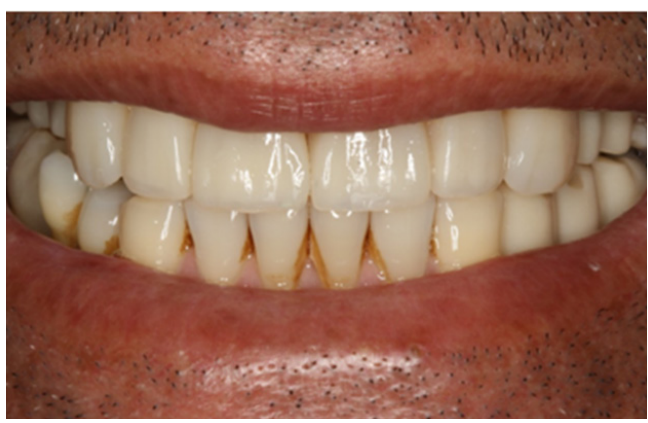

Figure 12 (A) Final appearance of the smile.

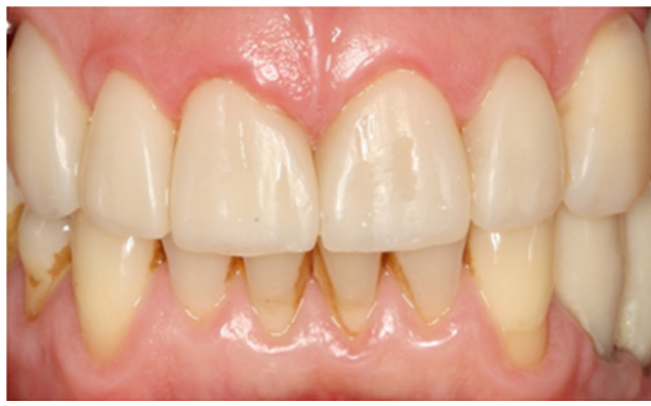

Figure 12 (B) Final appearance of the smile. 


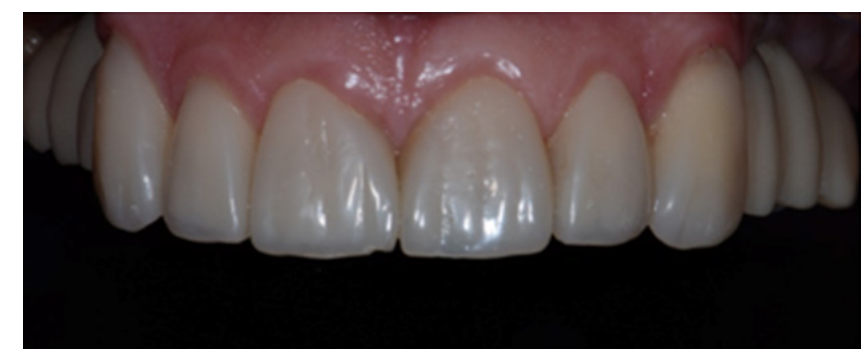

Figure 13 Two-Year follow-up.

\section{Discussion}

The use of direct composite resin restorations as treatment plan is based in the literature for their good properties and clinical performance. ${ }^{16}$ For success and longevity in this treatment, professionals should consider the type of composite resin, methods and materials to hybridization the tooth structure (enamel etching, self-etching, no etching), and the operative procedure (beveling of enamel margin, rubber dam application). ${ }^{16}$ The literature shows a high success rate for direct restorations with composite resin, provided they comply with the principles of restoration fabrication. It is observed $95 \%$ success rate for restorations class III and $90 \%$ for Class IV restorations after 10 years. ${ }^{16}$ The most recent innovation in the development of composites has been the "nanofill" composites, containing only nanoscale particles. Many manufacturers have been modifying their formulation micro hybrid composites by adding nanoparticles and possibly pre-polymerized resin fillers, similar to those found in the microfill composites, and have named this group "nanohybrids". ${ }^{17}$ In the clinical case it was used the composite resin IPS Empress Direct that is a light-curing, radiopaque, nano-hybrid composite. ${ }^{18}$ Nanohybrids composites are available in a variety of different colors and are ideal for esthetic restorations. These materials are considered universal composites as they can be used for most anterior and posterior applications based on their combination of strength and polish ability. ${ }^{17}$ These compounds have good mechanical properties and this reflects in his excellent clinical performance. Then, it is important that professionals know the properties of the material of choice for any type of treatment, since there are important factors for the success of a restoration over time. Some of the clinical phenomena could be explained by material-inherent properties. ${ }^{16}$ Among them, we can mention the color stability and surface texture, which directly influence smile esthetics. In this study, beyond the choice of a material with good optical properties, mixing of colors of composites it is an important factor for obtaining natural aesthetics. Reproduce dental tissues naturally are not an easy task. Dentin presents a chromatic translucency, with its saturation increasing over time. ${ }^{19}$ However, enamel has the ability to present either chromatic or achromatic translucency. ${ }^{20}$ Enamel and dentin composite resin have different compositions which try to reproduce the properties of tissues. Therefore, the choice of material and pigment is very important, because color perception of the dentin composite resin is influenced by the enamel composite resin selected. ${ }^{21}$ An important advantage of choosing by direct treatment is the repair possible without the need of replacing the restauration. The repair of composites resin is an important feature, and one that has only recently being investigated through formal studies. ${ }^{17}$ A recent study showed that performance of repaired restorations was similar to restorations which have been replaced, over the 10 years. This performance was based on the following parameters: marginal adaptation, secondary caries, and anatomy. ${ }^{22}$ It should be noted that the repair of composite should be the treatment of choice when it is clinically indicated, since it is a minimally invasive treatment that can increase consistently longevity of the restoration..$^{8-23}$ The success of direct adhesive restorations depends directly on the formation and stability of an excellent hybrid layer. ${ }^{23}$ In this study, seeking excellent adhesion between composite and enamel/dentine in addition to use of an adhesive system of three steps, we used the chlorhexidine after acid etching. Chlorhexidine has the ability to inhibit metalloproteinases and Cisteine Catpsine that are enzymes collagenolytic found in the dentin. ${ }^{15-25}$ These enzymes, once activated by acid etching, can degrade collagen fibrils including the adhesive system that infiltrate to form the hybrid layer. By inhibiting these enzymes, chlorhexidine help preserve the structural integrity of the collagen matrix in the hybrid layer, increasing the longevity of the union of resin-dentin interface..$^{24,25}$ In addition to factors related to the properties of materials and care while performing the direct restorative procedure as discussed above, the manual professional skill is a very important factor for a favorable aesthetic result. Therefore, the partnership with the dental technician is important in planning aesthetic rehabilitation. The size and form of the maxillary anterior teeth are important not only to dental esthetics, but also to facial esthetics and favorable occlusion. ${ }^{26}$ Integral planning of the case from the mount articulator to restore occlusal guides, as well as diagnostic wax, carried by the technician, are ways of giving predictability to the professional perform treatment safely. In the case presented in this paper, the partnership with the technical favored the aesthetic result due to the making of matrices from waxing. The technique shown using transparent silicone condensation was very favorable. This is due to the possibility of photoactivation the composite resin through the silicone matrix. Thus it was possible to transfer the anatomical details of shape and texture present in the wax for the final restoration. This greatly facilitates the work of the dentist, as this cosmetic result will not depend entirely on their manual skill to sculpt and anatomize teeth with composite resin. In addition improves the properties of composite resin, as this is light-cured in the absence of oxygen. This is an important advantage of using this buccal silicone guide. This last light curing resin layer of a restoration in the presence of oxygen causes the composite does not have a favorable degree of conversion which implies the decrease of mechanical properties. ${ }^{17}$ Moreover, the aesthetic is also impaired, giving an aspect of porosity to the composite. The polymerization of the resin through the buccal silicone guide matrix allowed absence of oxygen allowing more compact and smooth surfaces, thus promoting the aesthetics and providing better mechanical properties for the material, which influences the longevity of the treatment. Moreover, the planning of the work and waxing in articulator ensured fewer adjustments and restoring the occlusal stability of the patient. In this way the professional can transfer the correct relationship between the size and shape of the teeth, associated with a correct occlusion planned in articulator. This ensures greater predictability of the case and added security professional and patient regarding treatment. The aesthetic rehabilitation planning with direct composite resin is an excellent treatment option, if well planned. The professional must know the properties of the materials of choice and care in relation to the technique, so seeking longevity for rehabilitation. The functional planning of the occlusion through the mounting articulator is a step that cannot be neglected, and make use of alternatives to facilitate the sculpture of the anterior teeth, as shown in the present case, is a great way to ensure a favorable aesthetic result.

\section{Funding}

None. 


\section{Acknowledgments}

None.

\section{Conflicts of interests}

The author declares that there is no conflict of interest.

\section{References}

1. Cesario VA, Latta GH. Relationship between the mesiodistal width of the maxillary central incisor and interpupillary distance. J Prosthet Dent. 1984;52(5):641-643

2. Raj V. Esthetic paradigms in the interdisciplinary management of maxillary anterior dentition-a review. J Esthet Restor Dent. 2013;25(5):295-304.

3. Talarico G, Morgante E. The human dimension: esthetics in society and in medicine. Eur J Esthet Dent. 2013;8:136-155.

4. Lecocq G, Truong Tan Trung L. Smile esthetics: calculated beauty? Int Orthod. 2014;12(2):149-170.

5. Pontons-Melo JC, Pizzatto E, Furuse AY, et al. A conservative approach for restoring anterior guidance: a case report. $J$ Esthet Restor. Dent. 2012;24(3):171-182.

6. Schirra C. Loss of vertical dimension: extensive therapy in dentitions with erosion and abrasion. Quintessence Int. 2013;44(10):733-740.

7. Ardu S, Duc O, Krejci I. Amelogenesis imperfecta: a conservative and progressive adhesive treatment concept. Oper Dent. 2013;38(3):235-241.

8. Pontons-Melo JC, Furuse AY, Mondelli J. A direct composite resin stratification technique for restoration of the smile. Quintessence Int. 2011;42(3):205-211

9. Humel MM, Takahashi JM, Paulillo LA, et al. Direct restorative treatment of anterior weared teeth after re-establishment of occlusa vertical dimension: a case report. Gerodontology. 2012;29(4):299-307.

10. Gordan VV, Garvan CW, Blaser PK, A long-term evaluation of alternative treatments to replacement of resin-based composite restorations: results of a seven-year study. J Am Dent Assoc. 2009;140(12):1476-1484.

11. Shibata S, Taguchi C, Gondo R, et al. Ceramic Veneers and DirectComposite Cases of Amelogenesis Imperfecta Rehabilitation. Oper Dent. 2015;41(3):233-242.
12. Coachman C, Calamita M. Digital Smile Design: A Tool for Treatment Planning and Communication in Esthetic Dentistry. QDT. 2012.

13. Carrilho MR, Geraldeli S, Tay F, et al. In vivo preservation of the hybrid layer by chlorhexidine. J Dent Res. 2007;86:529-533.

14. Heintze SD, Rousson V, Hickel R. Clinical effectiveness of direct anterior restorations-a meta-analysis. Dent Mater. 2015);31(5):481-495.

15. Ferracane JL. Resin composite-state of the art. Dent Mater. 2011;27(1):29-38.

16. Blackham JT, Vandewalle KS, Lien W. Properties of hybrid resin composite systems containing prepolymerized filler particles. Oper Dent. 2009;34(6):697-702.

17. Terry DA, Geller W, Tric O, et al. Anatomical form defines color: function, form, and aesthetics. Pract Proced Aesthet Dent. 2002;14(1):59-67.

18. Mayoral JR, Arocha MA, Domínguez S. In vivo spectrophotometric evaluation of pure enamel and enamel-dentine complex in relationship with different age groups. J Dent. 2013;41(12):1245-1250.

19. Villarroel M, Fahl N, De Sousa AM,et al. Direct Esthetic Restorations Based on Translucency and Opacity of Composite Resins. J Esthet Restor Dent. 2011;23(2):73-88.

20. Fernández E, Martín J, Vildósola $\mathrm{P}$, et al. Can repair increase the longevity of composite resins? Results of a 10-year clinical trial. J Dent 2015;43(2):279-286.

21. Hickel R, Brüshaver K, Ilie N. Repair of restorations-criteria for decision making and clinical recommendations. Dent Mater. 2013;29(1):28-50.

22. Pashley DH, Tay FR, Yiu C, Hashimoto M, Breschi L, et al. Collagen degradation by host-derived enxymes during aging. $J$ Den Res. 2004;83(3):216-221.

23. Breschi L, Mazzoni A, Nato F, et al. Chlorhexidine stabilizes the adhesive interface: a 2-year in vitro study. Dent Mater. 2010;26(4):320-325.

24. Hasanreisoglu U, Berksun S, Aras K, et al. An analysis of maxillary anterior teeth: facial and dental proportions. $J$ Prosthet Dent. 2004;94(6):530-538 